\title{
Gentrificación en Chile: aportes conceptuales y evidencias para una discusión necesaria ${ }^{1}$
}

\author{
Ernesto López-Morales²
}

\begin{abstract}
RESUMEN
En Latinoamérica y Chile, en la última década, se observan intensos procesos de reestructuración urbana en zonas pericentrales, con recambio de clase social, lo que es comprendido bajo el apelativo de "gentrificación". El presente artículo ofrece una lectura crítica de aspectos teóricos esenciales del fenómeno de la gentrificación, enfatizando una distinción de lo que resulta regular (sustancial) versus lo anecdótico o visualmente contingente del proceso. Tal definición se estima útil para entablar un diálogo conceptual más fructífero y articulador con definiciones provenientes desde otras latitudes. En una segunda instancia, el artículo intenta corroborar una hipótesis explicativa del carácter estructuralmente político-económico del actual proceso de gentrificación en las principales ciudades chilenas, abordando el caso de Santiago como el más representativo. Se presenta evidencia y analiza incrementos de renta potencial monopólicamente capturada por inmobiliarias (RCS-2), a la par de procesos deliberados de devaluación de renta de suelo socialmente capturada (RCS-1), con consecuente desplazamiento social residencial.
\end{abstract}

Palabras clave: Gentrificación, renta de suelo, desplazamiento, exclusión, Santiago de Chile

\begin{abstract}
For the last decade, Latin America and Chile have seen intensive class-led processes of urban restructuring, namely gentrification. This article offers a critical revision of gentrification theory whilst emphasizing what is regular versus what is contingent (or particular) of the process, in order to better engage the local debate with the global academia. In a second part, the article substantiates a hypothesis about the politico-economic character of the processes of gentrification experienced by the major Chilean cities, focusing on the case of the inner city of Santiago as the most representative. We analyze evidence on potential increases in ground rent levels and the monopoly captured by real estate firms, as well as subsequently deliberate processes of capitalized ground rent devaluation and thus social displacement of low-income residents.
\end{abstract}

Key words: Gentrification, ground rent, displacement, exclusion, Santiago de Chile

\footnotetext{
1 Resultados del proyecto FONDECYT 11100337 "Rent gap, social agents and planning systems: A case-study analysis of the property-led gentrification of Santiago de Chile's inner city area". Investigador principal: Ernesto López Morales.
}

Artículo recibido el 17 de febrero de 2013, aceptado el 16 de mayo de 2013 y corregido el 25 de junio de 2013.

2 Departamento de Urbanismo, Universidad de Chile (Chile). E-mail: elopez@uchilefau.cl 
En el siglo XX, las grandes urbes latinoamericanas se caracterizaron por sus altos grados de industrialización y crecimiento demográfico. Actualmente, su característica principal bien podría ser la gentrificación de sus áreas centrales consolidadas, según plantean una serie de investigaciones recientes (Sandroni, 2006; Delgadillo, 2008; Herzer, 2008; Kanai \& Ortega-Alcázar, 2009; López-Morales, 2011, 2013; Contreras, 2011; Schlack y Turnbull, 2011; Inzulza-Contardo, 2012; Janoschka et al., 2013).

Eric Clark, uno de los autores más influyentes en este tema el mundo, define gentrificación como la reestructuración espacial de un área urbana mediante la inyección de capital fijo en mercado inmobiliario y de infraestructura, orientada al reemplazo de usuarios de ingresos medio-bajos por usuarios de poder económico superior, en un contexto de mercantilización de suelo (Clark, 2005). El presente artículo se apoya en esta definición.

La actual tendencia de transformación urbana en las grandes ciudades chilenas es problemática. Entre los años 2000 y 2010, en diez de los 11 distritos (comunas) central y pericentrales de la región de Santiago, el mercado inmobiliario de renovación residencial en altura se traduce en incrementos explosivos en el precio de venta de las unidades residenciales, desde 1.100 a $1.500 \mathrm{UF}^{3}$, con reducción del tamaño promedio de 70 a 50 $\mathrm{m}^{2}$, según el total de permisos de edificación solicitados ${ }^{4}$. No se requiere un análisis demasiado profundo para detectar una elitización de las zonas en renovación con cada vez una mayor exclusión de hogares extensos y/o de bajos ingresos, sin poder adquisitivo suficiente ni acceso a créditos bancarios y/o subsidio de renovación urbana (actualmente subsidio DS1, ex "Renovación Urbana").

\footnotetext{
3 De 25 a 34 millones de pesos chilenos (según valor UF de junio 2013, que equivale a \$22.800), o de US\$52.200 a 71.200 (según valor de cambio de dólar de la misma fecha). La UF es una unidad de cuentas utilizada en Chile, autoajustable según inflación.

4 Observatorio Habitacional MINVU (2011).
}

En paralelo, este mercado residencial privado intensifica el consumo de suelo para redesarrollo en altura por parte de las empresas inmobiliarias, mientras que el valor pagado por ese suelo es insuficiente para compensar a los residentes-propietarios y posibilitar su relocalización en condiciones habitacionales y locacionales similares. Si desde una perspectiva económica el actual valor de uso del suelo urbano central y pericentral no se equipara con su actual valor de cambio, desde una perspectiva social y ambiental, los supuestos efectos positivos de la gentrificación (ampliación y mejoramiento de oferta residencial y revitalización de medio ambiente construido ${ }^{5}$ ) son aminorados $\mathrm{O}$ desvirtuados por efectos del deterioro de la materia construida, la devaluación del suelo sujeto a eventual explotación, la expulsión social, y el hiperescalamiento de la nueva masa construida (Figura $N^{\circ} 1$ ), según confirman Borsdorf e Hidalgo (2013). Por otra parte, el sufrir expulsión desde el mercado inmobiliario residencial en zonas de renovación urbana, conlleva, para los desplazados, un aumento considerable del costo y tiempo de movilidad, y pérdida de centralidad (por menor acceso a bienes públicos cruciales para el desarrollo humano, principalmente oferta variada de empleo, salud municipal de relativa calidad, y oferta educacional municipal en liceos "emblemáticos", todo ello localizado en el pericentro).

Lo problemático de todas estas situaciones es que la cada vez más costosa oferta inmobiliaria residencial en altura en los 11 distritos pericentrales representa el 55\% del total de vivienda producida en la Región Metropolitana de Santiago. Tendencias similares de alza de la producción residencial en altura, en zonas consolidadas, respecto al total de vivienda producidas a nivel regional, se observan con claridad en otras metrópolis chilenas como Valparaíso, Antofagasta, Talca y Puerto Montt. Por otra parte, en las zonas periféricas urbanas tradicionalmente populares, también existe intenso desarrollo inmobiliario, aunque no de recambio de stock edificado, recibiendo oleadas migra-

\footnotetext{
5 Para una comparación exhaustiva entre efectos positivos y negativos de la gentrificación, ver Atkinson y Bridge (2005).
} 
torias de población de mayores ingresos que generalmente se emplazan en conjuntos cerrados elitistas. Problemático es, sin embargo, que los valores de suelo en la periferia urbana hayan aumentado en una proporción mucho mayor. En el caso de Santiago, esto ocurre en una proporción cercana al $1.000 \%$, entre 1990 y 2010 , con precios de suelo actualmente alrededor de $2 \mathrm{UF} / \mathrm{m}^{2}$ (Trivelli, 2011). Ello genera, entre otras cosas, que la locación de vivienda para segmentos populares (quintiles 1 y 2) desaparezca de la periferia compacta, como había sido la tónica en las últimas décadas, y se emplace en las zonas satelitales del extrarradio regional, amplificando las distancias y tiempos de desplazamiento a la ciudad consolidada para los más pobres (Hidalgo et al., 2007). Similares procesos de renovación urbana central, con consumo acelerado de suelo, y con potencial de desplazamiento, ocurren en el centro de Antofagasta, sector Brasil, y en Valparaíso, sector cerro Los Placeres. Asimismo, con menor fuerza pero mayor velocidad producto del deterioro postterremoto 2010, los casos de Talca y Curicó podrían estar siguiendo las mismas lógicas ${ }^{6}$. Si bien este artículo no se focaliza en esos casos regionales, se comprende que son estructuralmente similares, responden a las mismas condicionantes geográficas y económicas, y podrían tener los mismos efectos, que el caso de Santiago.

En resumen, si se acepta que existe desplazamiento residencial de los estratos populares desde los espacios pericentrales de la ciudad (algo que este artículo intenta corroborar), en el caso de Santiago, tales segmentos actualmente no encontrarían cabida ni siquiera al "interior" de las 34 comunas de la periferia compacta de la ciudad, ya que son expulsados hacia el extrarradio metropolitano producto de la "huida" de la producción inmobiliaria social, que a su vez es limitada por los incrementos de precios de suelo imperantes. Esto podría indicar que la gentrificación en la metrópolis de Santiago y, por extensión, en las principales ciudades de Chile que experimentan dinámicas inmobiliarias similares, no es un caso que atañe a barrios centrales históricos particularizados, sino que un proceso de segregación a gran escala, más sistémico de lo que se ha visto hasta ahora.

El presente artículo se estructura de la siguiente forma. Se define gentrificación a partir de algunos sesgos interpretativos locales, y luego se plantea una hipótesis que busca ser explicativa de los procesos de recambio social y geográfico, en zonas centrales y pericentrales, de la ciudad chilena. Se discuten, más adelante, conceptualizaciones teóricas que ayudan a explicar el fenómeno en términos estructurales y apoyan conceptualmente la hipótesis, finalizando con la exposición y discusión de evidencia generada a partir de una investigación empírica desarrollada en seis comunas del pericentro de Santiago.

Figura $\mathrm{N}^{\circ} 1$

Pasaje residencial con edificios de renovación urbana en el fondo, comuna de Santiago-

Centro

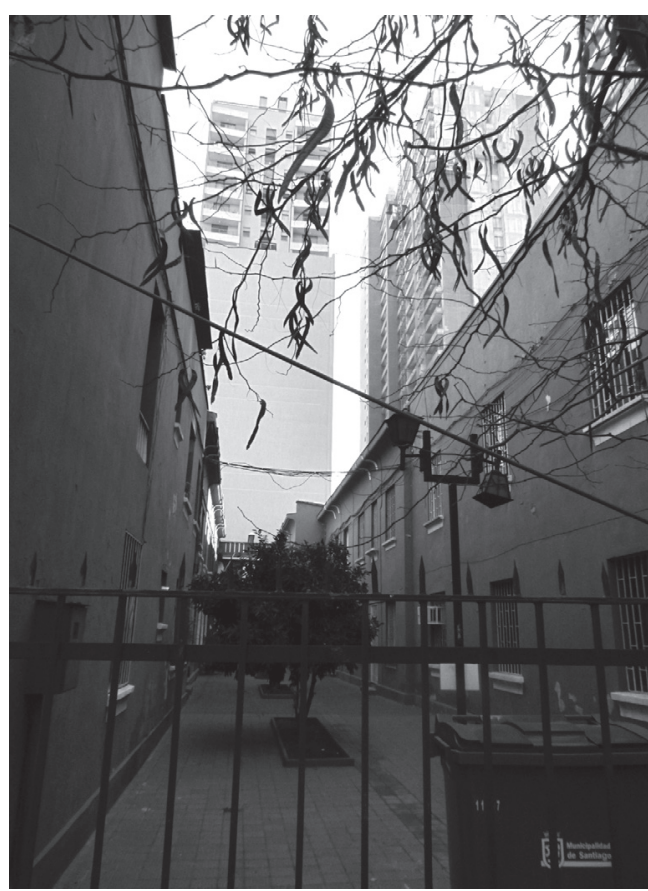

Fuente: Elaboración propia.

\footnotetext{
6 Ver http://www.fau.uchile.cl/extension/direccion-deextension/70994/gentrificacion-y-su-inclusion-endebate-de-ciudades-post-terremoto
} 


\section{Algunos sesgos y mitos acerca de la gentrificación en Chile}

Tratándose de un proceso de recambio urbano que probablemente marcará la pauta de la discusión en las próximas décadas, existen aún algunos mitos o sesgos sobre la gentrificación en Chile, necesarios de superar, a nivel mediático y académico. Los medios de comunicación mitifican la gentrificación como un proceso de sofisticación urbana "descubierto", incluso, a veces, "inventado", en Nueva York, Londres y/o París (etcétera)", con características visuales aparentemente comunes, a saber: transformaciones físicas a pequeña escala en barrios históricos o patrimoniales, un colorido e imagen urbana "auténticos" que son recuperados por una clase culturalmente refinada, un mercado floreciente de atracción de actividades conspicuas de servicio y consumo cultural, y una nueva componente social residente usualmente de alto estatus cultural o económico. En este sentido, barrios históricos en proceso de recambio inmobiliario, como Bellavista, Yungay o avenida Italia, en Santiago, o cerro Alegre en Valparaíso, son entendidos como una suerte de "réplicas" de casos norte-atlánticos y/o anglosajones, tradicionalmente conocidos a través de la literatura y los medios. Autores como Schlack y Turnbull (2011), Contreras (2011), e Inzulza-Contardo (2012) presentan análisis de gran nivel sobre gentrificación en Chile, pero, hasta ahora, sus investigaciones traslucen un cierto entendimiento de la gentrificación como un proceso privativo a barrios "históricos", respondiendo a una casuística urbana particularizada, análoga, al menos en lo visual, a contextos norteamericanos o europeos.

Usualmente, se les supone, a los nuevos residentes, niveles altos de agenciamiento sobre las transformaciones de la estructura física y social de la ciudad, como si estas respondieran en exclusiva a su voluntad y poder en tanto consumidores de vivienda y servicios de alto estatus. Algunos comentaristas incluso se refieren a los "gentries" chi-

\footnotetext{
7 Resulta curioso que muchos sigan recurriendo a los estudios y descripciones de barrios londinenses que realizó la socióloga Ruth Glass jen 1964!
}

lenos. Erróneamente, se asume que son estos quienes deben generar evidencia visible de su mayor poder económico o capital cultural, como condición necesaria para la existencia de gentrificación, de forma también análoga a los casos tradicionales del norte global. Es decir, la gentrificación tiene que verse, sentirse, olerse como tal (en un nivel de subjetividad realmente asombroso). Esto conlleva un problema epistemológico, pues solo se estudian tautológicamente sectores urbanos ya preconcebidos como casos de gentrificación. Se desconoce, por otro lado, el poder de las decisiones que afectan las inversiones inmobiliarias a micro y macroescala, por parte de productores inmobiliarios, bastante menos glamorosos en lo visual, pero que son quienes finalmente toman las principales decisiones de localización, regulan la demanda a través del manejo de la oferta residencial, y generan los cambios físicos y sociales en los barrios, como se analiza aquí más adelante. Tampoco se reconoce la alta incidencia que tiene el Estado, a través de sus instrumentos de regulación de la construcción inmobiliaria que, a la corta y a la larga, van recomponiendo física y socialmente la ciudad.

Algunos sostienen que la renovación en altura no genera gentrificación porque no "expulsa" residentes, en la medida en que existe el mito de que los espacios pericentrales son territorios "vaciados" poblacionalmente (supuesto discutible, ya que el censo de 2002 indicaba una población de 1,3 millones de residentes en los 11 distritos pericentrales de Santiago, es decir, prácticamente un cuarto de la población metropolitana de entonces). Se sostiene además que a mayor demanda por suelo para renovación urbana, mayor apreciación de los terrenos, lo que a la larga beneficiaría a los propietarios/residentes originales que se mantienen allí, dotándoles de un mayor poder adquisitivo $y$, por ende, mejores posibilidades de relocalizarse in situ, dentro de los barrios gentrificados. Todas estas apreciaciones llevan aparejada la idea (muy pregnante) de que la gentrificación no solo no genera exclusión social, sino que opera como fuente de mejoramiento urbano en zonas deprimidas, atrayendo además empleo, servicios, comercio y consumo, es decir revitalizando la economía local, supuesto que ha sido popularizado como de "gentrificación positiva" (Sabatini et al., 2010). 
Como se intenta exponer aquí, tal estado de situación está lejos de ocurrir en el centro y pericentro de Santiago.

\section{Una hipótesis para la gentrificación en Chile}

La renovación urbana en altura es la forma más dominante y problemática de gentrificación en Chile. Ello no excluye la existencia de formas de gentrificación más acotadas, y de menor intensidad inmobiliaria, en barrios "históricos", aunque tales casos probablemente son comparativamente marginales, por la escasa población afectada en términos de expulsión. La gentrificación en ciudades chilenas es social y espacialmente mucho más abarcativa de lo que se le supone, en escala, magnitud de la inversión financiera involucrada, tipo de agentes participantes, y sus prácticas; es decir, es un problema de política pública habitacional, complejo y mayúsculo.

En segundo término, la gentrificación de áreas urbanas consolidadas depende de una característica primordial del mercado inmobiliario, y que son los ciclos previos de devaluación del suelo y reacondicionamiento y/o renovación posteriores de ese suelo. Ello comprende un precio bajo recibido por los propietarios (sean estos residentes o no residentes) por la venta de su suelo, con una disminución considerable del potencial de encontrar vivienda de reemplazo por parte de los hogares residentes (sean estos propietarios, allegados multiocupantes o incluso arrendatarios), en un contexto de incremento constante de precios de vivienda nueva. Es decir, exclusión socioeconómica espacial de las zonas de mercado residencial (Aalbers, 2011) o, más concretamente, una combinación de "presión de desplazamiento" y "desplazamiento exclusionario" (Slater, 2009), como se explica en la sección siguiente.

Tercero, siguiendo la definición de Clark (2005), los gentrificadores son los usuarios que intervienen y modifican el medio construido. Esto implica que no son necesariamente los nuevos residentes quienes realizan esa acción. Para decirlo claramente, los gentrificadores chilenos son aquellos con el poder político y económico suficiente para generar los cambios espaciales ocurridos y producir desplazamiento social y la tendencia a la homogeneización socioeconómica en los barrios. En el caso chileno, los gentrificadores son los desarrolladores inmobiliarios, es decir, quienes demuestran el mayor grado de agenciamento para elitizar el mercado residencial, absorber la ganancia generada en la construcción inmobiliaria, y producir los cambios físicos a una escala sin precedentes en la historia de las ciudades chilenas ${ }^{8}$.

Cuarto, la gentrificación, por su macroescala imperante en Santiago y las grandes ciudades chilenas, responde fuertemente a influjos de capital financiero reconvertido en inmobiliario y la necesidad de fijar capital en el espacio con el fin de reproducir su volumen y tasa de retorno. Evidentemente, la lógica locacional de la gentrificación y su intensificación en el espacio dependen más del potencial de ganancia o rent gap ("brecha de renta", de aquí en adelante, según la traducción de López-Morales, 2008) existente, y menos de los cambios culturales o preferencias de consumo de ciertos "ambientes exclusivos" que puedan encontrarse, a simple vista, en algunos barrios tradicionales de la ciudad.

Quinto, la gentrificación incrementa la escala de la segregación, al desposeer la mayor parte de la renta del suelo a quienes tradicionalmente la poseen, expulsando del pericentro a quienes no tienen capacidad de pago extra para permanecer, es decir, los dos quintiles más bajos de la población, con alta probabilidad de ser relocalizados en el espacio regional distante, producto de los incrementos en el precio de suelo periférico metropolitano y de la vivienda allí producida.

Sexto y último, la gentrificación chilena depende de políticas e instrumentos, estatales y municipales, de regulación de suelo, que operan con el fin de atraer actividad inmobiliaria por medio de maximizar el potencial de

\footnotetext{
8 Se desvirtúa así la discusión con la que algunos pretenden "culpabilizar" a los nuevos residentes en barrios gentrificados, así como a algunos académicos que estudian gentrificación al tildarlos también como gentrificadores "intelectuales". Revisar el interesante, a la larga agotador, debate entre Tom Slater $(2009,2010)$ y Chris Hamnett (2009, 2010).
} 
ganancia privada por redesarrollo inmobiliario, así como incluso desplazar la actividad inmobiliaria desde una zona de mercado ya saturado, a otra zona aún no renovada.

En resumen, la gentrificación en Chile es un proceso de reestructuración espacial con recambio social de grupos de menor a mayor ingreso y capital social, asociado con una inyección de capital inmobiliario en zonas focalizadas, que son posibilitadas por regulación estatal. Fundamentalmente, aunque no únicamente, las manifestaciones visibles de la gentrificación en Chile son distintas a aquellas provenientes de la imaginería popularizada en países de la órbita norte-atlántica y/o anglosajones, tratándose más bien de un proceso que, en el caso chileno, asume una forma de recambio de stock edificado residencial, a gran escala y considerable altura y densidad, dominado por agentes productores no residentes, y que genera niveles altos de exclusión, desplazamiento social y segregación a escala regional, aunque no elitismo cultural.

\section{Gentrificación: lente analítico para los estudios urbanos en contextos neoliberales}

La teoría de la gentrificación ofrece un potente lente analítico para comprender la economía urbana en un contexto de predominio de mercado y sus lógicas rentabilizadoras. La gentrificación en sí es un problema de extracción y distribución desigual de la ganancia obtenida por el uso del suelo, y una distribución desigual en el acceso a los bienes públicos urbanos localizados centralmente; todo ello posibilitado, y a veces conducido, por el Estado.

La contribución de la teoría marxista contemporánea a este tema ha sido fundamental. Eric Clark $(1987,1988,1995)$ y Neil Smith $(1979,1996)$ fueron quienes primero se dieron cuenta de que la brecha de renta es una pieza clave para comprender el origen y dinámica de la gentrificación, sin importar la forma física que esta asuma. La brecha de renta es el diferencial entre la renta actual "capitalizada" y una renta futura "potencial" de carácter monopólico, maximizada por las ventajas ofrecidas de infraestructura y servicios, y las regulaciones públicas de construcción.
Se debe entender renta de suelo como la ganancia extraíble a partir de las condiciones de suelo urbano, descontados los costos de demolición, reconstrucción y venta. La renta de suelo capitalizada no es lo mismo que precio de suelo, ni tampoco que la mal Ilamada "plusvalía de suelo", siendo lo primero un valor fijado por oferta y demanda que no es necesariamente capitalizado, y la segunda, un incremento de precio medido a partir de un cierto nivel inicial arbitrariamente determinado ${ }^{9}$.

La brecha de renta se amplifica en la medida la renta capitalizada disminuye, o bien en la medida en que la renta potencial aumenta por diversos motivos. La renta urbana potencial se constituye como oligopólica (o "monopólica de clase", según Harvey, 1974) en la medida que las posibilidades tecnológicas y financieras, son concentradas en un grupo más o menos compacto de agentes inmobiliarios, generalmente no residentes de las zonas en transformación, y que se constituyen como la única posibilidad de materializar dicha renta. Mientras más alto es el coeficiente de constructibilidad, la renta potencial es capturable por un número menor de actores con capital, acceso al financiamiento y/o créditos suficientes, capacidad de acumular suficiente suelo para desarrollar proyectos, y capacidad tecnológica avanzada de construcción y cumplimento de las complejas normas legales y comerciales de edificación. De tal forma, la renta potencial se configura esencialmente como una renta monopólica, reflejo de un poder de clase.

La renta potencial, o para efectos de este artículo, Renta Capitalizada de Suelo 2 (RCS2), depende de la regulación gubernamental (controles de la planificación, la provisión de infraestructura, subsidios, o incluso presión por cambios reglamentarios mucho más allá del lobby públicamente reconocido en las esferas nacionales o municipales). Asimismo,

\footnotetext{
9 Hablar de "plusvalía de suelo" es un contrasentido, pues según la teoría del valor, el "plusvalor" equivale al valor de la fuerza de trabajo añadido en el proceso de producción de un bien determinado, no aplicándose en este caso a los incrementos de la renta de suelo urbano, siempre originados por factores externos.
} 
la renta potencial es amplificada en Chile por la inexistencia de mecanismos de "captura de plusvalías" (Smolka y Amborski, 2003; Sandroni, 2011), lo que la hace ser también muy elástica (Hackworth, 2002). Ello obviamente depende de un contexto neoliberal, en el que el Estado garantiza normativas que intensifican la inversión concentrada en lugares específicos como una "facilitación" para la fijación del capital y su anclaje al lugar (Harvey, 1989). Al mismo tiempo, el Estado deja de invertir en cambios normativos en lugares "no competitivos" pero sí en aquellos en "regeneración", configurando un juego de suma-cero sin evidencia de que haya chorreo hacia otras zonas (MacLeod, 2002; López-Morales et al., 2012; Peck, 2005; Shin, 2009b, Wacquant, 2008). Se trata de una definición concreta de neoliberalismo urbano en su fase actual, es decir, fijación del capital en espacios de alta rentabilización, y expansión de las lógicas de mercado como reguladores de toda la vida urbana (Harvey, 2005; Peck y Tickel, 2007; Salazar, 2003).

La renta de suelo urbano tiene una propiedad "ascendente", ya que se genera a partir del pago por uso del suelo pero se filtra siempre hacia arriba, no hacia abajo, como un chorreo invertido. El curso de la renta de suelo puede ser de la siguiente forma: una transferencia de dinero desde los grupos de ingresos bajos o medios (pequeños propietarios de suelo, o eventualmente arrendatarios) a la burguesía dominante del mercado inmobiliario, siempre en tránsito, a través del diferencial de renta monopólica, terminando finalmente en las esferas financieras (Harvey, 1985). Es decir, un traspaso de uso y propiedad, y luego recirculación (reinversión) de la renta en el mercado inmobiliario en forma de capital, o una escalada de esa renta hacia ámbitos financieros en forma de dinero; o ambos casos. Pero, si bien el capital fluye hacia circuitos globales, singularmente todos los gobiernos locales, incluidos aquellas administraciones identificadas como progresistas o derechamente antineoliberales, terminan obligados a jugar este juego de rentabilización del suelo (Peck y Tickell, 2002), ya que no solo el Estado opera en el mercado, sino las lógicas de mercado opera dentro del Estado, a través de sus múltiples canales y redes de comunicación e influencia (Ward, 2003; Molotch, 1993).
La producción y acumulación monopólicas de la renta potencial implican algún grado de despojamiento del potencial económico que esta ofrece. La renta potencial, al ser monopólicamente capitalizada, depende no solo del incremento de su límite máximo producido por la cabida de suelo, en base a las modificaciones intencionadas de instrumentos de regulación urbanística y de construcción, sino de la capacidad de reducir el valor de la renta capitalizada de suelo, es decir, reducir al máximo posible el pago por ese suelo. Esto se produce ya sea por medio de un pago monopsónico al antiguo propietario, al momento de la transacción en la compra venta de suelo (es decir, pocos o solo un comprador de suelo que controlan el mercado; usualmente, la empresa inmobiliaria o el agente que la representa, quienes están en disposición de determinar el precio), como a través de la reducción más directa e intencionada del precio de ese suelo a través de acciones concretas tendientes al deterioro de las propiedades en un sector o barrio entero inclusive. Por ende, rentas capitalizadas disminuidas y rentas potenciales amplificadas son hechos relacionados dialécticamente, como lo verifica para Santiago Borsdorf e Hidalgo $(2013)^{10}$.

Aparecen en la literatura varias formas directas e intencionadas de devaluación de suelo. La compra de una sola parcela en una manzana entrega a ese comprador inmobiliario un poder mayor al momento de enfrentar las siguientes negociaciones con el resto de los propietarios (es regla general que las otras inmobiliarias se restarán de comprar predios en esa manzana). En la jerga inmobiliaria chilena, esto se denomina como "pinchar la manzana", proceso estructuralmente similar al blockbusting anglosajón ${ }^{11}$. Luego, tal pre-

\footnotetext{
10 De una forma más lineal, Jason Hackworth (2002, 2007) define la trayectoria de la gentrificación en los EE.UU., en una primera fase previa al año 2000 de creación de rent gap por disminución de la renta capitalizada (gentrificación prerrecesionaria) y, en una segunda fase dependiente de la amplificación artificial de la renta potencial (gentrificación postrecesionaria). Tal es una forma parecida a las lógicas de rentabilización de suelo en el mercado urbano chileno, a partir de la década de 1990.

11 Para el caso chileno, revisar http://diario.elmercurio. com/detalle/index.asp? id $=\{c c e 0 c 7 f d-7 f 70-44 c c-$ 9c3e-04814ab6029c\}
} 
dio puede ser demolido, abandonado, o dejado al arbitrio temporal de residentes indeseables, dependiendo del grado de urgencia que se tenga para continuar con el proceso de acumulación de suelo antes de iniciar el proceso de reconstrucción. Otra forma identificada es la fijación de ordenanzas públicas que, dentro de una determinada área, "castigan" la pequeña inversión de reparación o ampliación residencial, pero a la vez premian la gran inversión inmobiliaria. Ello es una variante de lo que denomina como redlining en la literatura internacional (Smith, 1979; Aalbers, 2011), y está presente en Chile desde los desincentivos a la subdivisión predial con incentivos a la fusión predial, existentes en la Ordenanza de Urbanismo y Construcciones, pasando por el discrecional flujo de subsidios, por parte de algunos municipios pericentrales, al pequeño emprendimiento inmobiliario (López-Morales, 2011), hasta los seccionales locales que sobretarifican los permisos de obra menor, cuando se trata de propiedades bajo cuatro pisos de altura, como ocurrió en Santiago-Centro, sector Santa Isabel, hasta el año 2007.

Una renta de suelo baja, capitalizada por un núcleo familiar residente, en este caso denominada como RCS-1, no equipara el valor de uso de la propiedad o el espacio residencial que se transa, ergo ella implica una desposesión concreta del potencial de pago por residencia de reemplazo en el mismo u otro lugar. Ya hemos planteado que la gentrificación, más que simplemente "reemplazo" de población, es una reestructuración urbana que genera desposesión de los valores de uso y cambio del suelo urbano, con un desplazamiento espacial o exclusión social en el acceso a la vivienda. En cualquier caso, un reemplazo de población es de por sí una forma de desplazamiento, ya que no se puede reemplazar una cosa por otra si no se "remueve" la anterior del mismo espacio. Una renta de suelo baja expone a quien capitaliza esa renta a obtener un bajo poder económico para comprar vivienda de recambio, sobre todo en la medida en que el mercado residencial predominante en los últimos veinte años apunta a precios de vivienda cada vez más altos.

Los trabajos de Slater (2009), inspirados en Marcuse (1985), permiten abordar este tema con bastante nitidez. Según estos au- tores, el desplazamiento (expulsión) ocurre cuando un hogar es forzado a mudarse de residencia por condiciones que afectan la vivienda o su espacio exterior inmediato, condiciones que: 1) van más allá de las posibilidades de ese hogar de controlar o prevenir; 2) ocurren a pesar que el hogar previamente ha cumplido con todas las condiciones (impuestas) para ocupar ese espacio; y 3 ) hacen imposible, peligrosa o insostenible económicamente seguir habitando ese lugar.

De tal forma, según Slater (2009), al menos se pueden leer cuatro formas de desplazamiento:

a) Desplazamiento directo (de "último residente"): Propiamente expulsión, ocurre cuando los propietarios arrendadores cortan los servicios y fuerzan a los ocupantes a desalojar, cuando se producen aumentos de valor en los arriendos o impuestos territoriales insostenibles para los habitantes, o cuando el Estado hace uso de derechos expropiación con el fin de evacuar una determinada área.

b) Cadena de desplazamiento: Proceso previo al punto anterior, ya que deben ser considerados residentes desplazados con anterioridad, en la medida en que el barrio o la unidad urbana decaen. No olvidar que la dialéctica vaciamiento/gentrificación es un proceso largo que puede tomar varios años o décadas.

c) Desplazamiento exclusionario: Se refiere a hogares que no pueden tener acceso a espacio urbano (propiedades, suelo, viviendas) ya que han sido abandonadas o gentrificadas (se aplica para ambos casos). El proceso de "desplazamiento exclusionario" reduce considerablemente las oportunidades de localización y/o de encontrar vivienda en el lugar o espacio equivalente, para hogares de nivel socioeconómico bajo que habitan el mismo lugar, o para hogares de nivel socioeconómico bajo que habitaban con anterioridad dicho espacio.

d) Presión de desplazamiento: Se refiere a la desposesión (real o potencial) que sufren hogares de bajo ingreso económico durante la transformación de la estructura 
espacial asociada a la gentrificación, producto del encarecimiento de los costos de vida, o acciones de devaluación de su propiedad a transar en el mercado.

Si bien los cuatro tipos de desplazamiento existirían desde hace al menos dos décadas en el centro y pericentro de Santiago, el presente trabajo analiza los dos últimos tipos. Los conceptos de "desplazamiento exclusionario" y "presión de desplazamiento" se conciben, para el caso chileno, como efecto de prácticas devaluatorias de renta de suelo, acometidas por la clase inmobiliaria sobre las áreas centrales, pudiendo concebirse como la principal forma en la cual se realiza la gentrificación en Santiago de Chile. Para que se genere este desplazamiento, los residentes se ven compelidos, de diversas formas, a vender sus propiedades mediante prácticas inmobiliarias de, primero, devaluación, y luego, desposesión de la renta de suelo.

Si para muchos observadores europeos y norteamericanos, la gentrificación es clásicamente difícil de concebir sin una práctica activa de los rentistas de forzar el desplazamiento de los arrendatarios (Smith, 1996), en el contexto chileno, dicha práctica existe en el marco de las tensas relaciones que se dan entre el capital inmobiliario y los pequeños propietarios que residen en el pericentro. El proceso de gentrificación entonces genera la situación de que los residentes están en condiciones de desplazarse hacia otras localizaciones, siempre y cuando la porción de brecha de renta que son capaces de absorber por la venta de su propiedad, los habilite para ello. Pero no solo son gentrificados aquellos que están dentro de las áreas centrales y que experimentan la presión de desplazamiento, sino también aquellos que históricamente han estado dentro de dichas zonas y que, como grupo o clase social, no pueden acceder a estas áreas pericentrales, denegándose a unos el "derecho a la permanencia" (Newman \& Wyly, 2006), y a otros, de bajos ingresos, las posibilidades de una "vuelta al centro".

Una menor centralidad asociada al desplazamiento residencial "exclusionario" se agrava por factores tan cruciales como la pérdida de cercanía al trabajo, y a la salud y educación públicas de calidad, ambos factores presentes en el pericentro e imprescindibles para la preproducción social de los segmentos que lo habitan (Butler, 2007; Butler \& Robson, 2001). Baste revisar el discurso del activismo urbano chileno ${ }^{12}$ para darse cuenta que el problema político acaecido en prácticamente todo el pericentro de Santiago no radica en una reacción en contra de la llegada de nuevos residentes, sino que contra la imposición de mecanismos amplificadores de renta potencial de suelo, y agentes de mercado inmobiliario, muchas veces desatados que, con asistencia de las administraciones territoriales municipales, intensifican la dialéctica destrucción/reconstrucción de las áreas urbanas en disputa, en busca de la captura monopólica de esas mayores tasas de ganancia posibles, generando exclusión social (López-Morales, 2013).

La gentrificación es, entonces, problemática, solo si se le comprende como una economía política basada en la desposesión de las riquezas del suelo y el desplazamiento social, y cuando el acento investigativo deja de estar situado en gentrificadores visibles y culturalmente conspicuos, para enfocarse en los gentrificadores invisibles, cuyas manifestaciones y motivaciones son económicas, y que son los que realmente producen los cambios urbanos. Sin embargo, es necesario que también los gentrificados sean visibilizados a través del estudio de los procesos de desplazamiento que ellos experimentan, según reclaman autores contemporáneos fundamentales (Atkinson \& Bridge, 2005; Lees et al., 2008; Slater, 2006; Wyly et al., 2010). Asimismo, en casos donde la intensidad de la gentrificación se correlaciona con la intensidad y escala de la producción inmobiliaria, como el de las ciudades metropolitanas chilenas con dinámicas de renovación urbana intensas, se deben problematizar los instrumentos de fijación de la constructibilidad del suelo como los conductores principales para la distribución desigual de la renta, según se aprecia en trabajos de distinta proveniencia (Darling, 2005; Shin, 2009a; Wyly et al., 2010). Parafraseando a Swyngedouw (2009), la investigación en gentrificación revelaría que el espacio urbano es mucho menos una

12 http://mplchile.cl 
ciudadanía culturalmente atractiva y despolitizada, y mucho más una arena de disputa político-económica y ambiental.

\section{Rol del Estado en la renovación urbana con gentrificación del pericentro de Santiago}

Desde comienzos de la década de 1990, la estrategia pública chilena de renovación urbana en grandes ciudades se ha basado en subsidiar a la demanda, con un monto fijo de 200 UF $(10 \%$ de un costo máximo admisible de vivienda nueva a subsidiar), a pagar a postulantes con alta capacidad de ahorro de un fondo mínimo de también 200 UF. En Santiago, el efecto del subsidio en términos de repoblamiento intercensal 1992-2002 fue magro, con un crecimiento negativo poblacional promedio de las comunas pericentrales de $-11 \%$, versus un $24 \%$ de crecimiento del resto de las 23 comunas que componen el Área Metropolitana de Santiago, confirmando un proceso de despoblamiento observado en las tres décadas anteriores, pero que de cualquier forma mantenía a cerca de un cuarto de la población metropolitana del momento, habitando el pericentro. Sin embargo, en el periodo intercensal 2002-2012, las mismas 11 comunas del pericentro aumentaron en promedio un $7 \%$ de población, en una contratendencia producida por el boom inmobiliario y la inyección de un número creciente de usuarios nuevos atraídos por la oferta de renovación urbana, con un total de 230.000 unidades residenciales producidas entre 1990 y 2008. A partir del año 2006, las 11 comunas del pericentro de Santiago ocupan un $57 \%$ del total de la superficie de vivienda autorizada para construcción en toda la Región Metropolitana de Santiago ${ }^{13}$.

\footnotetext{
${ }^{13}$ Entre 1992 y 2002, pese al boom inmobiliario residencial, el "decepcionante" crecimiento negativo demográfico intercensal de las comunas central y pericentrales de Santiago, hizo que el gobierno y municipios removieran el término de "repoblamiento" de sus planes y estrategias, a partir de entonces utilizando el de "renovación urbana" solamente. A partir de los resultados inversos que se esperan del Censo 2012, es probable que el uso del término "repoblamiento" aparezca de nuevo en la jerga de política pública como un resultado positivo
}

Desde 1990, los planes reguladores de todas las comunas del pericentro del Gran Santiago (con excepción de Pedro Aguirre Cerda) han incorporado normativas de edificación, complementadas con normas de excepción existentes en la Ordenanza General de Urbanismo y Construcción, que maximizan la renta potencial de suelo, tales como el incremento de la constructibilidad por lote, la exención impositiva por fusión predial, el incremento de constructibilidad del suelo por normativa especial de "conjunto armónico", normas de fachada continua con altura de 35 metros con volumen superior aislado, y normas de "cono de sombra" que amplifican el potencial construible (por sobre la normativa de rasantes, anteriormente ocupada). Por lo general, la orientación pro renovación urbana es también explícita en las memorias de los planes reguladores y sus evaluaciones ambientales. Operan también, en varios municipios pericentrales, réplicas de la Corporación de Desarrollo de Santiago (CORDESAN), formada en 1985, y que fuera exitosa en gatillar en Santiago-Centro el incipiente boom inmobiliario de comienzos de la década de 1990.

Contra toda creencia del Estado "regulador", casi la totalidad de los actuales municipios urbanos pericentrales chilenos se comportan como agentes de mercado "oferentes" de volúmenes atractivos de constructibilidad de suelo para la explotación intensiva en altura. La evidencia indica que, eventualmente, podría haber competencia entre municipios, e incluso a costa del desarrollo de otros municipios, con nichos saturados y otros de reemplazo (trade-off). Actualmente pareciera ser más realista hablar de un "urbanismo pro empresarial" como el modelo de gestión urbana imperante a nivel municipal, con una fuerte dependencia municipal a las carteras de proyectos prioritarios regionales y sectoriales del gobierno central, dependencia al Fondo Común Municipal chileno, así como una búsqueda de recursos provenientes de patentes comerciales, y especialmente del impuesto municipal directo a la construcción, consistente en un $1,3 \%$ del costo total declarado de la obra (López-Morales et al., 2012).

de los subsidios estatales y las políticas municipales de suelo. 
Figura $\mathrm{N}^{\circ} 2$

División comunal para el proceso de actualización del PRC de Santiago con las fechas de aprobación por etapas.

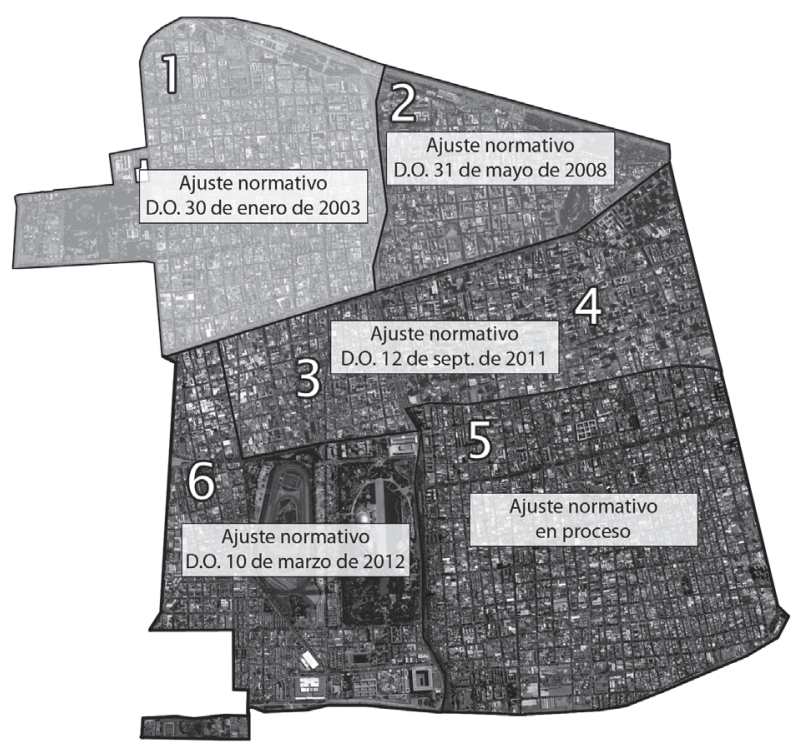

Fuente: Elaboración propia en base a PRCS

El municipio de Santiago-Centro es también emblemático al ser capaz de desplazar la inversión privada inmobiliaria, dentro de su territorio, de una zona a otra, mediante ajustes en las normativas de suelo. Su Plan Regulador está dividido en seis zonas (Figura $N^{\circ} 2$ ), con una primera actualización de su plan en 2003, limitando, para la Zona 1, la altura de edificación a cuatro pisos. En consecuencia, el capital inmobiliario migró hacia otras zonas con condiciones aún flexibles y favorables, siendo el sector Santa Isabel, localizado en la Zona 3, el que entonces adquirió la mayor actividad inmobiliaria, con alrededor de 110 edificios residenciales de 14 a 31 pisos, construidos desde 2005 en adelante. Los coeficientes de constructibilidad normados para esta zona eran de 12 veces la superficie del predio (lo que expresa la línea discontinua en Figura $N^{\circ} 3$ ), pero los coeficientes de constructibilidad en cada año realmente logrados por los proyectos construidos ascendieron hasta alcanzar un máximo de 11, en 2008, lo que se interrumpe a partir de 2011. En ese año, nuevos ajustes municipales nuevamente redujeron la constructibilidad permitida en la Zona 3, y trasladaron la acti- vidad inmobiliaria hacia el sur de la comuna, especialmente a las Zona 5, que aún ofrece coeficientes de constructibilidad altos, pese a que la nueva autoridad municipal, asumida en 2012, "congeló" los permisos de anteproyectos de edificios, ya aprobados ${ }^{14}$. En el caso de Ñuñoa, sector Irarrázaval Poniente, como muestra la misma Figura $N^{0} 3$, la modificación del Plan Regulador Comunal en 2003, con amplificación del coeficiente de constructibilidad normado, fue íntegramente aprovechada entre 2006 y 2010.

\section{Oligopolio inmobiliario y desposesión de renta de suelo en la gentrificación del pericentro de Santiago}

Los datos discutidos en esta sección responden a resultados de un análisis desarro-

\footnotetext{
$14 \mathrm{http}: / / \mathrm{w} w \mathrm{w}$. Iatercera.com/not i c i a / santiago/2013/02/1731-508007-9-torres-en-mattasur-se-duplicaran-pese-a-congelamiento-de-permisos.shtml
} 
Figura $\mathrm{N}^{\circ} 3$

Evolución de Coeficiente de Constructibilidad normado y real en Santiago-Centro, Santa Isabel y Ñuñoa, Irarrázaval Poniente.

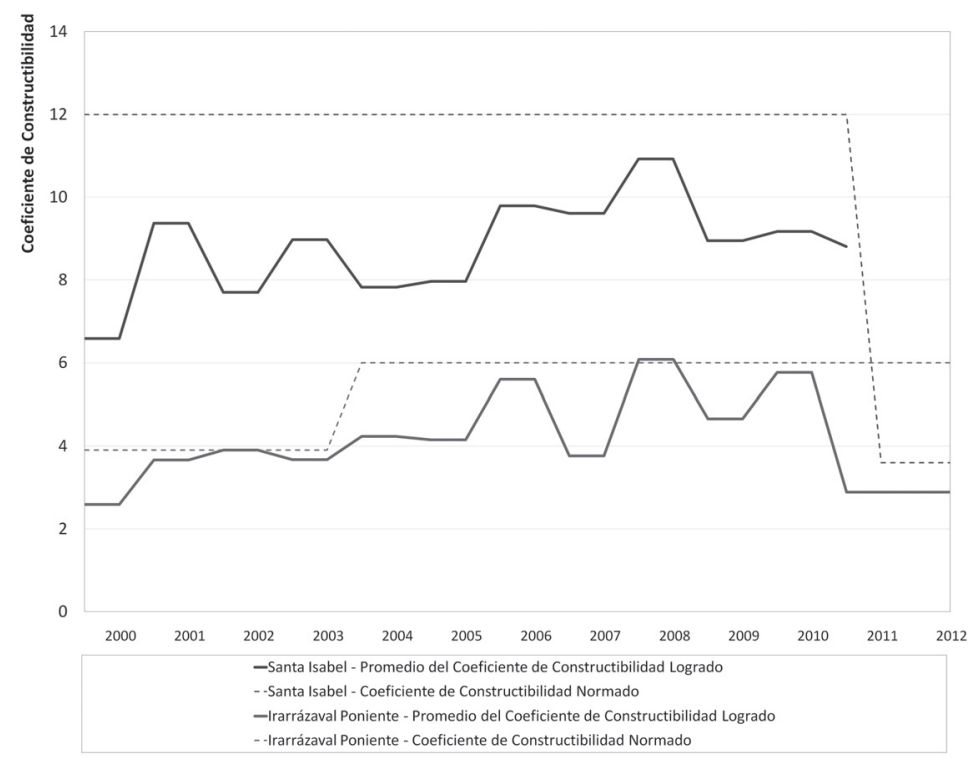

Fuente: Elaboración propia en base a PRCS y análisis proyectos inmobiliarios

llado en zonas de desarrollo urbano en seis distritos (municipios) del sector pericentral de Santiago, a saber comunas de Santiago-Centro, Recoleta, Independencia, Quinta Normal, Macul y Ñuñoa, que se ilustran en la Figura $N^{\circ}$ 4. En la sección siguiente, se comentarán resultados de la comuna de Santiago, sector Santa Isabel, espacio que actualmente lidera por lejos la producción inmobiliaria residencial por $\mathrm{m}^{2}$ en toda la región, y que se configura como uno de los casos más críticos de gentrificación en Chile, así como el más representativo de lo que sucede en el pericentro de Santiago y de otras ciudades nacionales.

Se analizaron los dos tipos de rentas de suelo, obtenidas respectivamente por residentes pequeño-propietarios (RCS-1) y redesarrolladores inmobiliarios (RCS-2). De los primeros, se analizaron 498 transacciones de compraventa de terrenos y 433 predios que fueron comprados por inmobiliarias entre 2000 y 2010, y posteriormente explotados a través de edificación en altura en 163 edificios residenciales analizados (según procesamiento a partir de Conservador de Bienes Raíces de Santiago). La renta potencial cap- turada por inmobiliarias se calculó comparando del total de ganancia por ventas en los edificios residenciales producidos durante el mismo lapso, descontados costos de producción, es decir costos de suelo + construcción + ventas. Todos los valores son procesados en UF y UF/m². Adicionalmente, durante 2012 se aplicó una encuesta a 746 predios aún no desarrollados y actualmente habitados, inmersos dentro de las zonas de estudio, lo que permitió identificar número de hogares residentes, tamaño de esos hogares, ingreso familiar promedio, estatus de la tenencia (vivienda propia, en arriendo, multiocupada, allegados, etc.), comuna de trabajo y/o estudio, casos de compra de predios aledaños por parte de inmobiliarias, entre otros factores. El error muestral fue de menos de $7 \%$, en las zonas según cantidad de habitantes de acuerdo a proyección del Censo 2002, sumando la población de las manzanas comprendidas en las zonas de estudio.

El total del pericentro de Santiago (11 comunas) actualmente absorbe el 55\% de las unidades residenciales producidas en una región donde actualmente el $60 \%$ de la vivienda se produce vía departamento en con- 
dominio en altura. La producción de vivienda en la comuna de Santiago-Centro es comparativamente alta; entre 2002 y 2011, se autorizan allí 97.921 unidades, en abierto contraste con las comunas de Ñuñoa (26.544), San Miguel (12.885), Quinta Normal (8.492), Recoleta (8.301), Estación Central (6.760) e Independencia (6.031). Para el año 2007, el sector Santa Isabel, representaba el $60 \%$ de la nueva superficie residencial construida en la comuna de Santiago-Centro, con una suma de producción cercana a los 370 mil metros cuadrados, comparable a la producción de toda la comuna de Ñuñoa para ese mismo año (para el total de la muestra seleccionada en esta investigación, ambas comunas concentran el $76 \%$ de producción inmobiliaria).

En el caso del sector Santa Isabel, sus ventajas comparativas en términos de constructibilidad ofrecida significaron el arribo, a partir de 2005, de inmobiliarias provenientes de comunas del barrio alto, o especializadas en desarrollos en zonas costeras. A la fecha, en esta comuna, un $53 \%$ de los proyectos han sido producidos por cuatro grandes empresas desarrolladoras, a saber: Paz Froimovich, Euro, Absal y RVC. Euro además domina el $30 \%$ de la producción en las comunas de Recoleta e Independencia, controlando la totalidad de la producción de 2012 en la comuna de Independencia.

Existe, en los seis casos estudiados, una captura de renta de suelo altamente dispar, entre propietarios residentes o arrendadores y los desarrolladores que compran suelo para capturar su renta maximizada. Como muestra la Figura $N^{\circ}$ 5, no existe una lógica espacial pero sí temporal en la generación de brecha de renta al interior de las zonas de renovación urbana; es decir, los proyectos que capturan "brechas de renta" menores son aquellos desarrollados en etapas iniciales del proceso de renovación urbana en el sector, existiendo las mayores capturas en etapas

Figura $N^{\circ} 4$

Zonas de estudio en el pericentro de Santiago.

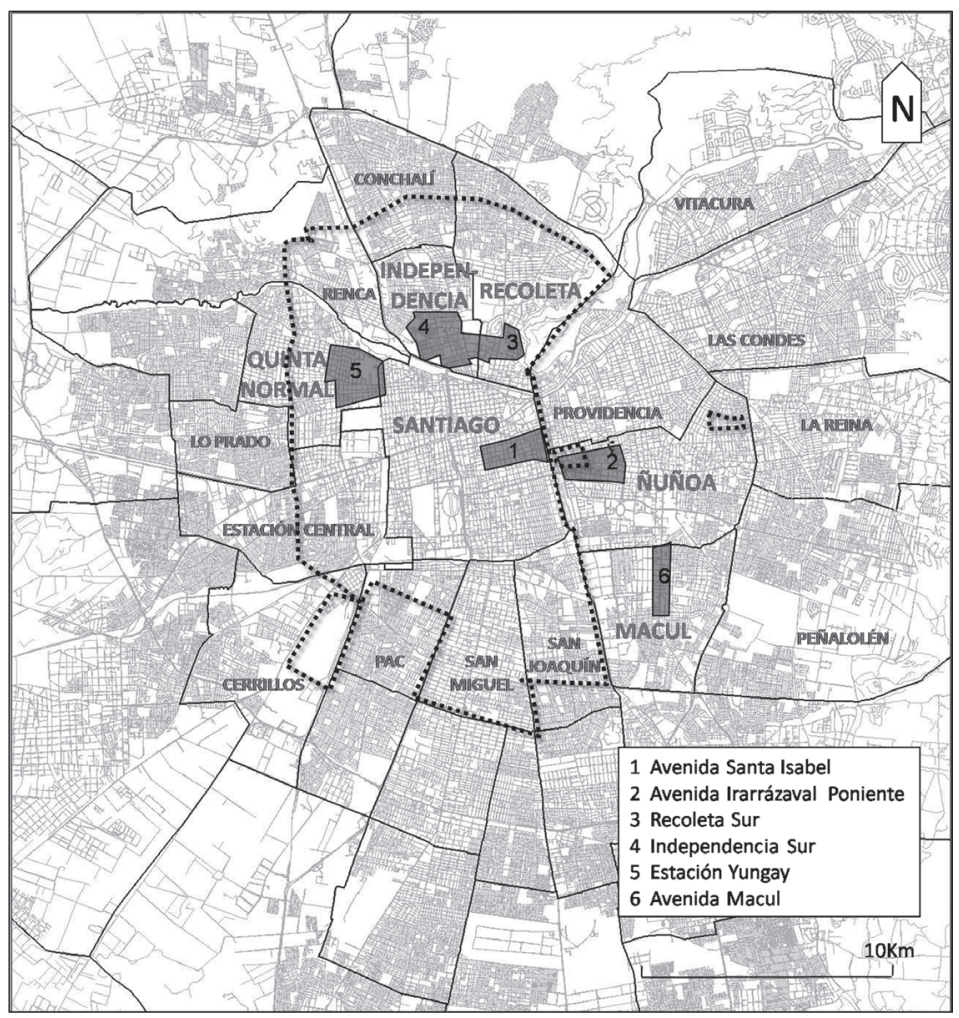

Fuente: Elaboración propia. 
Figura $\mathrm{N}^{\circ} 5$

Localización de proyectos en Santiago-Centro y Ñuñoa, con gráfico comparativo de rentas potencial (RCS-2) y capitalizada (RCS-1)

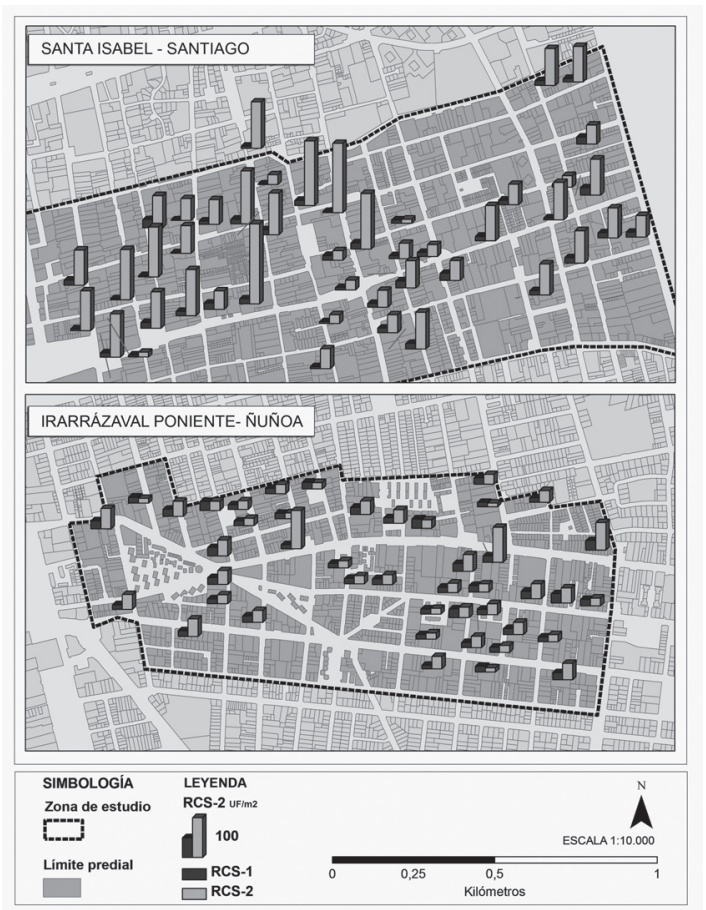

Fuente: Elaboración propia

Figura $\mathrm{N}^{\circ} 6$

Trayectoria de rentas de suelo capturadas por empresas inmobiliarias (negro) tras proyecto de redesarrollo en altura, versus rentas "sociales" capturadas por propietarios pequeños de suelo (rojo), 2000-2012, comuna de Santiago

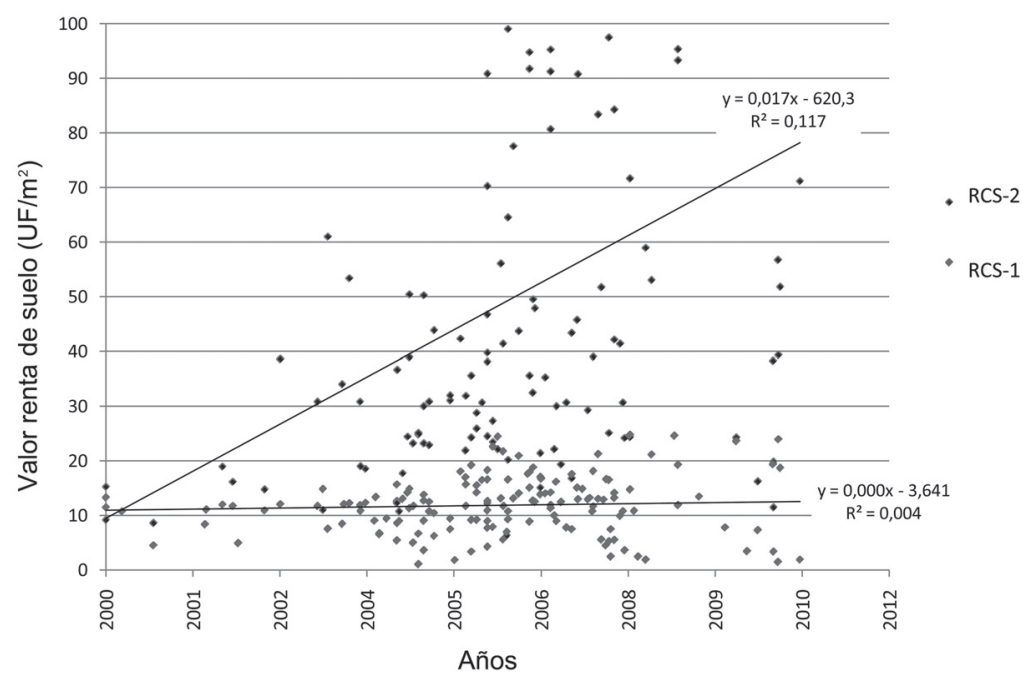

Fuente: Elaboración propia. 
posteriores. Sin embargo, ello no ocurre con la renta capitalizada por los pequeños propietarios de suelo.

La Figura $\mathrm{N}^{\circ} 6$ muestra que, entre 2000 y 2012, la diferencia entre el valor obtenido por el desarrollador (RCS-2) y el valor obtenido por el pequeño propietario (RCS-1, sea residente o arrendador) es cada vez más dispar en el tiempo. Es decir, a mayor demanda por suelo no hay mayor precio de suelo pagado ni enriquecimiento por parte de los pequeños propietarios, a la vez que pareciera existir un "aprendizaje" de las inmobiliarias en términos de optimización de la ganancia a partir de su inversión, manipulando la magnitud de sus proyectos, e incrementando el precio de venta de sus departamentos. La curva de tendencia de la renta capitalizada (por pequeños propietarios) muestra una relativa estabilidad, con un leve incremento de en torno a 11 a $13 \mathrm{UF} / \mathrm{m}^{2}$, mientras que una renta potencial es fácilmente obtenible por más de 10 veces, incluso 14 veces, ese valor. En la realidad, como lo demuestran la mayoría de los datos estudiados, a mayor demanda de suelo ejercida por agentes inmobiliarios oligopólicos, el precio de oferta del suelo se mantiene constante. Lo que hay es un ensanchamiento de la brecha de la renta, proceso que en esta caso al menos dura diez años.

Sin embargo, aún prima la creencia de considerar que una supuesta escasez de suelo disponible en las ciudades chilenas estaría encareciendo el precio de la vivienda nueva en su interior, falacia imaginada a partir de lo presupuestado por modelos teóricos neoclásicos y no los datos reales. Los factores que realmente incidirían en el aumento drástico del precio de venta de las viviendas nuevas construidas en el pericentro radican en lo que se denomina como "colusión tácita del mercado residencial chileno", es decir, un acuerdo de fijación de precios incrementales entre el escaso número de inmobiliarias dominantes (Lefort \& Vargas, 2011). Ese incremento es actualmente aducido por error a una "burbuja inmobiliaria", y produce un acceso cada vez más restringido de segmentos sociales a las zonas en renovación.

Para el periodo estudiado, la mayor captura de brecha de renta por productores inmobiliarios ocurre en el sector Santa Isabel, donde el conjunto de los agentes rentistas y capitalistas que intervienen logran una media de $91 \mathrm{UF} / \mathrm{m}^{2}$ de suelo desarrollado. Luego se ubica Irarrázaval Poniente con $48 \mathrm{UF} / \mathrm{m}^{2}$. Tercero se emplaza el sector Recoleta con $40 \mathrm{UF} / \mathrm{m}^{2}$, y luego Macul, Quinta Normal e Independencia en torno a las $35 \mathrm{UF} / \mathrm{m}^{2}$. Actualmente, la relación entre lo que obtiene el segmento empresarial versus los pequeños propietarios de suelo, es decir, lo que denominamos como "tasa de acumulación", se expresa con valores más altos en SantiagoCentro $(11,7)$ y Quinta Normal $(10,9)$, mientras la zona con menor tasa es Ñuñoa $(2,2)$. Los casos de Macul, Independencia y Recoleta tienen en promedio tasas levemente sobre 3 (ver Figura № 5 con mapeo de esta relación para los casos Santiago-Centro y Ñuñoa).

Por otra parte, las rentas obtenidas socialmente en el sector Santa Isabel de la comuna de Santiago nunca superan los $20 \mathrm{UF} / \mathrm{m}^{2}$ en promedio por proyecto, y en una media circulan en las $10 \mathrm{UF} / \mathrm{m}^{2}$. La diferencia entre Ñuñoa (comuna tradicionalmente de "clase media") y Santiago-Centro, radica en la capacidad dispar de los hogares residentes de acceder a datos de mercado y asesoría legal previo a la venta de su suelo, aunque ello difícilmente ocurre en el sector Santa Isabel. Según los datos de nuestra encuesta, tal disparidad de "concurrencia" se correlaciona claramente con el estatus socioeconómico y educacional de dichos hogares.

Esto indica que en Santa Isabel y Quinta Normal, los propietarios-residentes obtienen una menor porción relativa de brecha de renta respecto a lo que obtiene el desarrollador inmobiliario por la venta de sus proyectos. Por su parte, Ñuñoa es una zona de alta brecha de renta pero con una tasa de acumulación más baja, lo que se debe a una participación alta de los propietarios originales respecto a la renta obtenida por los agentes inmobiliarios (con $16 \mathrm{UF} / \mathrm{m}^{2}$ promedio recibido por los propietarios residentes).

La Figura $\mathrm{N}^{\circ} 6$ muestra una tendencia alcista de la renta potencial RCS-2 (oligopólicamente capturada por inmobiliarias) entre 2000 y 2010 en el conjunto de las zonas del pericentro estudiado. Entre el año 2000 y 2001, las empresas en promedio no alcanzaban las $20 \mathrm{UF} / \mathrm{m}^{2}$, cifra que ya al 2005 se 
duplica alcanzando siempre valores sobre $40 \mathrm{UF} / \mathrm{m}^{2}$. Los años 2006 y 2007 son los que cuentan con mayor cantidad de registros y permiten hablar de un aumento importante de brecha de renta en el período en estudio, en extremo comparando 2000 y 2007, donde el registro para este último llega a $74 \mathrm{UF} / \mathrm{m}^{2}$, casi siete veces lo obtenido en el año 2000. Al final del período, la brecha de renta absorbida por el mercado de renovación urbana logra ser $488 \%$ más alta respecto del inicio del mismo. Por otra parte, como ya ha sido planteado, la renta de suelo "socialmente" capitalizada prácticamente no aumenta en el período, lo que implica una cada vez mayor tasa de acumulación.

En los seis casos municipales analizados, existe una disparidad de información al momento de negociar una compraventa de suelo. En Santiago-Centro, producto de la tendencia oligopólica del mercado, en un $55 \%$ de las veces la transacción se dará entre una persona natural y una empresa inmobiliaria grande. Esto se agrava por la existencia de dispositivos orientados a la reducción deliberada del valor de compra venta, tales como las prácticas de "pinchar manzanas", detectado en un $35 \%$ de los casos encuestados, con un número alto de propiedades compradas por inmobiliarias, y luego abandonadas o subutilizadas, lo que devalúa el entorno de la manzana. Como ya se ha mencionado, tal procedimiento fija una condición monopsónica, a favor de las empresas, al momento de gestionar la compra al resto de los propietarios adyacentes. Ni siquiera hemos considerado los otros factores de deterioro ambiental que también generan devaluación de la renta capitalizada de suelo, tales como los conos de sombra, pérdida de privacidad visual, contaminación acústica, y saturación de redes de transporte y servicios, producidos por la proliferación de condominios en altura en los barrios estudiados.

\section{Presión de desplazamiento y desplazamiento exclusionario en la comuna de Santiago Centro}

El análisis de desagregación que hemos realizado para la producción inmobiliaria se presenta, por razones de espacio, específicamente en el sector Santa Isabel, comuna de Santiago-Centro. En 2012, los datos muestran que en un $90 \%$ de los casos se produce vivienda de uno o dos dormitorios que en promedio no excede los $45 \mathrm{~m}^{2}$ (Cuadro $\mathrm{N}^{\circ}$ 1) y que en precio bordea las 1.700 UF. Esto implica que, por ejemplo, un predio de 150 $\mathrm{m}^{2}$ pagado a $10 \mathrm{UF} / \mathrm{m}^{2}$ implica un poder de compra sin deuda de un departamento de 40 $\mathrm{m}^{2}$ a lo sumo, en el que quedan excluidos integrantes allegados o más allá de dos hijos. Por estas dos características solamente, precio y tamaño de la vivienda nueva, la oferta de vivienda existente de por sí ya es excluyente de hogares arrendatarios, multiarrendatarios (usualmente inmigrantes) más extensos que cuatro integrantes, o con tasas de allegamiento variables.

La encuesta aplicada a 195 predios localizados en el sector Santa Isabel, expuestos a compraventa para renovación, muestra que un $53 \%$ de los casos son habitados por propietarios, mientras que un $40 \%$ son habi-

Cuadro $\mathrm{N}^{\circ} 1$

Desagregación de la producción residencial en comuna de Santiago, 2000-2012

\begin{tabular}{|l|r|r|r|}
\hline & Deptos 1D & Deptos 2D & \multicolumn{1}{c|}{ Deptos 3D } \\
\hline Cantidad unidades producidas & 4.271 & 4.722 & 1.024 \\
\hline Porcentaje del total & 43 & 47 & 10 \\
\hline Precio promedio departamentos (UF) & 1.145 & 1.678 & 2.248 \\
\hline Superficie promedio departamentos $\left(\mathrm{m}^{2}\right)$ & 29,15 & 44,64 & 61,66 \\
\hline Precio UF $/ \mathrm{m}^{2}$ & 39,3 & 37,6 & 36,5 \\
\hline
\end{tabular}

Fuente: Elaboración propia en base a estudio de oferta inmobiliaria. 
tados por arrendatarios y un $7 \%$ por multiocupantes que arriendan cuartos en una misma vivienda ("neoconventillos"). En un 20\% se observaron casos de allegamiento, es decir, más de un hogar compartiendo la misma residencia, lo cual dificulta la relocalización potencial dentro del mercado residencial en el sector o en un lugar de similares características. En promedio, los residentes encuestados han permanecido en el sector por 22 años, y en un $69 \%$ trabajan o estudian en la misma comuna.

De los arrendatarios encuestados, en un $57 \%$ perciben un ingreso familiar promedio inferior a $\$ 600.000$, con un promedio de 3,8 integrantes por hogar, mientras que en un $73 \%$, de los hogares que arriendan cuartos, su ingreso familiar es inferior a \$300.000, con un promedio de 2,9 integrantes por hogar. En ambos casos, su poder de pago es inferior al exigible para acceder a vivienda de reemplazo suficiente para absorber su tamaño familiar y que esté emplazada en la misma comuna. En el caso de los arrendatarios, en promedio estos residen en la misma propiedad desde hace 15 años, en un 50\% trabajan o estudian en la misma comuna, y en un $60 \%$ lo hacen en la misma comuna o comuna aledaña a Santiago-Centro. En el caso de los arrendatarios de cuartos, en un $63 \%$ trabajan o estudian en la misma comuna y han residido en la misma vivienda en promedio por 11,7 años. Como se ve, se trata de un universo de actores residentes cuya capacidad de relocalización con permanencia en la misma comuna es bastante precaria, y para quienes, en un $33 \%$, la expectativa de relocalización en otra comuna es vista como altamente perjudicial por la pérdida de centralidad, y para otro $33 \%$ la expectativa es imposible sin un subsidio y aporte adicional financiero.

El 53\% de residentes del sector son propietarios, pero estos aún presentan una alta precariedad al momento eventual de vender y relocalizarse. Para este análisis, estimamos tres bandas de valores de pago por suelo (RCS-1), a partir de los precios reales de compraventa de lotes ya registrados entre 2000 y 2010. Estos valores son 20,5 UF/m² (alto), $12,2 \mathrm{UF} / \mathrm{m}^{2}$ (regular), y $7,3 \mathrm{UF} / \mathrm{m}^{2}$ (bajo). Asimismo, se consideraron en el análisis el tamaño de cada propiedad a vender, el tamaño del hogar que habita cada una de esas propiedades, y la relación tamaño/precio de la vivienda ofertada en la misma zona requerida por ese hogar.

El precio "alto" de 20,5 UF/m² es un valor bastante improbable en términos generales, pero que podría ser pagado al primer vendedor en una operación hipotética de compra de varios lotes por parte de una inmobiliaria, con el fin de "pinchar" la manzana. Suponiendo que todos los 103 residentes propietarios fueran a recibir este precio por la venta de sus predios (considerando los distintos tamaños de sus propiedades), un $21 \%$ de estos quedaría incapacitado económicamente de encontrar vivienda de tamaño adecuado para absorber su grupo familiar. Si el precio pagado fuera el "regular" de 12,2 UF/m², habría al menos un $50 \%$ de hogares excluidos por incapacidad de encontrar vivienda equivalente. Si el precio pagado fuera "bajo" de 7,3 UF/m², un 75\% de los casos entraría en la categoría de "desplazamiento exclusionario", es decir, sin capacidad económica de acceder a la vivienda nueva localizada dentro de su propia zona residencial. Consideramos que el precio regular es el más probable, y configura una probabilidad general de $50 \%$ de desplazamiento en condiciones económicas desventajosas, es decir, la renta de suelo pagada mediante transacción inmobiliaria no equipararía un valor socialmente justo para posibilitar relocalización en condiciones similares de calidad, centralidad y acceso a bienes públicos. Casos similares se observan en Recoleta y Ñuñoa, donde un $40 \%$ de los propietarios residentes no alcanza a solventar relocalización residencial con el promedio de renta de suelo (RCS-1) que se captura por residentes en esas zonas. Los casos de Macul y Quinta Normal son más benignos, con un 25\% de desplazamiento exclusionario por razones de mercado, medido en precios promedio. En cualquier caso, los efectos gentrificadores del mercado residencial en el pericentro de Santiago, así como con alta probabilidad en otras zonas pericentrales metropolitanas del país, son evidentes y preocupantes.

\section{Conclusiones}

En Santiago, existen al menos tres procesos paralelos, a saber: i) un encarecimiento 
sostenido del precio de la vivienda en zonas pericentrales, junto con una reducción de su tamaño promedio, en una magnitud que supera las medias nacional y metropolitanas; ii) una ganancia creciente obtenida por desarrolladores en altura, en desmedro de un precio de suelo bajo y estático pagado a los propietarios al momento de la compraventa de suelo, lo cual configura un caso de "presión de desplazamiento" combinado con "desplazamiento exclusionario" para los dos quintiles más bajos residentes o potencialmente inmigrantes a la vivienda nueva producida en zonas consolidadas metropolitanas; y iii) subvención indirecta estatal a agentes productores de mercado, a través de subsidio a la vivienda clase media (subsidio DS1, ex "Renovación Urbana") con control de las ordenanzas de suelo y edificación, ambas condiciones necesarias para la captura privada de rentas de suelo. Es decir, gentrificación a gran escala, apoyada por el Estado.

El modelo de renovación urbana dominante en Chile dista de ser un proceso de regeneración urbana similar al experimentado en barrios particularmente elitizados de ciudades europeas o norteamericanas, más bien se trata de una construcción política orientada a la localización de extensas zonas de desarrollo inmobiliario, generadora de altas rentas de suelo monopólicamente capturadas, y con zonas intermedias donde se acelera el declive físico y económico por especulación con los predios y las manzanas. Este mercado depende de instrumentos públicos reguladores del suelo, que son muy eficientes en posibilitar la captura de las máximas ganancias de suelo por los agentes empresariales privados, o incluso reducir la renta de suelo capitalizable socialmente, con una incidencia tal que excluye de la compra de vivienda nueva al menos a los dos quintiles más bajos de la población. Tratándose de espacios urbanos consolidados, es preocupante que cerca de un $60 \%$ de arrendatarios y casi un $100 \%$ de multiocupantes están siendo actualmente excluidos de estos espacios residenciales, por razones económicas.

Este modelo, en la medida en que se expande, también expulsa propietarios residentes, al no encontrar estos, en al menos un $50 \%$ de los casos existentes en SantiagoCentro, una suficiente compensación eco- nómica por suelo vendido que les permita encontrar vivienda de reemplazo en similares condiciones de centralidad (en la misma comuna o comunas de mejores condiciones urbanísticas) ni acceso a servicios, más bien configurándose como una pérdida patrimonial, el alejamiento de los residentes de bajos ingresos de las infraestructuras públicas educacionales, de salud y recreación. Es bastante probable que similar dinámica ocurra en los casos de renovación urbana intensa de otras ciudades grandes chilenas, aunque la medición específica de estos casos está por verse. En cualquier caso, ya resulta posible aducir, con poco temor a equivocarse, que la renovación urbana chilena, más que producir medio ambientes urbanos socialmente revitalizados, homogeniza hacia arriba el estatus socioeconómico de la población pericentral, e incrementa la escala de la segregación a nivel metropolitano y regional, es decir, produce gentrificación (expulsión de estratos sociales de bajos ingresos) a una escala sin precedentes en el pasado.

En un país que se acerca a tener una tasa de población urbana del $90 \%$, el tener ciudades que no posibilitan el encuentro social interclases, especialmente en los espacios centrales urbanos simbólicamente más representativos y socioeconómicamente provistos de las mayores y mejores condiciones de ascenso social, es una condena a la anomia y la conflictividad social.

Ante la eterna y falsa disyuntiva entre expandir o compactar la ciudad, recurrentemente socorrida en los debates urbanísticos chilenos, se aduce generalmente que el actual modelo de renovación urbana sería la solución factible para reducir la presión por más expansión metropolitana. Sin embargo, como se aprecia en el análisis aquí presentado, tal solución resulta ser equivocada, ya que la densificación residencial en zonas centrales lo que está actualmente generando en realidad es una expulsión residencial centrífuga de los estratos populares, ergo mayor presión en las periferias más distantes. La teoría de la brecha de renta (rent gap) aparece hoy como un lente imprescindible para observar regulaciones públicas y conflictos de poder generados alrededor de la distribución desigual de las riquezas originadas en el suelo urbano y sus efectos de desplazamiento. 
Por el contrario, una teoría de gentrificación solo enfocada en transformaciones culturales y que "busca" manifestaciones directamente visibles, de similar forma a aquellas experimentadas en países norte-atlánticos y/o anglosajones, resulta inútil para comprender tales procesos.

Resulta imperativa la existencia de una política pública urbana que implemente una serie de medidas de corte regulatorio, a la gentrificación creciente de las ciudades grandes chilenas. Lo que se debe lograr es una renovación urbana social y económicamente sustentable, y eso pasa en primer lugar por regular las tasas de captura y acumulación de la altísima renta potencial de suelo generada. Si bien el Estado chileno está imposibilitado constitucionalmente para fijar montos máximos de ganancias por rentas de suelo por parte desarrolladores inmobiliarios, sí puede implementar formas de recuperar parte de esas altas (mal Ilamadas) "plusvalías" en la medida que quede claro que estas son aumentadas a través de regulaciones de la constructibilidad de suelo o la provisión de bienes públicos entregados por el mismo Estado. En segundo lugar, el Estado puede aplicar sistemas de compra preferente o bolsas de suelo estatal con fines sociales. Una vez controladas las variables "precio de suelo" y "recuperación de renta de suelo", se puede incentivar y gestionar el acceso al suelo y la construcción de un extenso número de viviendas populares en altura media, dentro de zonas pericentrales metropolitanas.

Es importante comprender el proceso de gentrificación urbana de manera global, extraerlo del simplismo de una casuística visiblemente atractiva en lo cultural y mediática, y entrar de lleno a reconocer que los profundos recambios experimentados por nuestros espacios metropolitanos, actualmente liberados al arbitrio del libre mercado inmobiliario y que, de no mediar cambios, seguirán atentando contra una mayor equidad y acceso territorial a los bienes públicos urbanos. Por supuesto que no todos los casos renovación urbana en Chile implican gentrificación, pero sí toda transformación radical del espacio residencial pericentral debe ser sujeto de cuidadoso escrutinio con el fin de prevenir y, llegado el caso, evitar el desplazamiento de clase, asociado a la superexplotación del suelo con fines mercantiles.

\section{Referencias bibliográficas}

AALBERS, M. Place, Exclusion and Mortgage Markets. Oxford: Wiley-Blackwell, 2011.

ATKINSON, R. \& BRIDGE, G. Gentrification in a Global Context: The new urban colonialism. Oxon: Routledge, 2005.

BORSDORF, A. e HIDALGO, R. Revitalization and tugurization in the historical centre of Santiago de Chile. Cities, 2013, № 31, p. 96-104.

BUTLER, T. For gentrification? Environment and Planning A, 2007, Vol. 39, p. 162-181.

BUTLER, T. \& ROBSON, G. Social Capital, Gentrification and Neighbourhood Change in London: A Comparison of Three South London Neighbourhoods. Urban Studies, 2001, Vol. 38, No 12, p. 2145 - 2162.

CASGRAIN, A. y JANOSCHKA, M. Gentrificación y resistencia en las ciudades latinoamericanas. El ejemplo de Santiago de Chile. Andamios, mayo - agosto 2013, No 22.

CLARK, E. The order and simplicity of gentrification - a political challenge. In: ATKINSON, R. \& BRIDGE G. Gentrification in a Global Context: The new urban colonialism. Oxon: Routledge, 2005, p. 256-264.

CLARK, E. The Rent Gap and Urban Change: Case Studies in Malmö 1860-1985. Lund: Lund University Press, 1987.

CLARK, E. The Rent Gap and Transformation of the Built Environment: Case Studies in Malmo 1860-1985. Geografiska Annaler. Series B, Human Geography, 1988, Vol. 70, $N^{\circ} 2$, p. 241-254.

CLARK, E. The Rent Gap Re-examined. Urban Studies, 1995, Vol. 32, N 9, p.1489-1503.

CONTRERAS, Y. La recuperación urbana y residencial del centro de Santiago: Nuevos habitantes, cambios socioespaciales signi- 
ficativos. EURE, 2011, Vol. 37, No 112, p. 89-113.

DARLING, E. The city in the country: wilderness gentrification and the rent gap. Environment and Planning A, 2005, Vol. 37, $N^{\circ} 6$, p. 1015-1032.

DELGADILLO, V. Repoblamiento y recuperación del Centro Histórico de la ciudad de México, una acción pública híbrida. ECOnomía, Sociedad y Territorio, 2008, Vol. 8, No 28, p. 817-845.

GLASS, R. London-Aspects of Change. Londres: Macgibbon \& Kee, 1964.

HACKWORTH, J. Post-recession gentrification in New York City. Urban Affairs Review, 2002, Vol. 37, Nº, p. 815-843.

HACKWORTH, J. The neoliberal city: Governance, ideology, and development in American Urbanism. Cornell: Cornell University Press, 2007.

HAMNETT, C. The new Mikado? Tom Slater, gentrification and displacement. City - Analysis of Urban Trends Culture Theory Policy and Action, 2009, Vol. 13, $\mathrm{N}^{\circ} 4$, p. 476-482.

HAMNETT, C. 'I am critical. You are mainstream': a response to Slater. City - Analysis of Urban Trends Culture Theory Policy and Action, 2010, Vol. 14, N 1, p. 180-187.

HARVEY, D. Class-Monopoly Rent, Finance Capital and the Urban Revolution. Regional Studies, 1974, Vol. 8, No 3-4, p. 239-255.

HARVEY, D. The urban process under capitalism: a framework for analysis. En: HARVEY, D. The Urbanization of Capital: Studies in the History and Theory of Capitalist Urbanization, Baltimore: The Johns Hopkins University Press, 1985, p. 91-121.

HARVEY, D. From Managerialism to Entrepreneurialism: The Transformation in Urban Governance in Late Capitalism. Geografiska Annaler. Series B, Human Geography, 1989, Vol. 71, $\mathrm{N}^{\circ} 1$, p. 3-17.
HARVEY, D. A Brief History of Neoliberalism. New York: Oxford University Press, 2005.

HERZER, H. (editor). Con el corazón mirando al sur: Transformaciones en el sur de la ciudad de Buenos Aires. Buenos Aires: Espacio Editorial, 2008.

HIDALGO, R.; ZUNINO, H. y ÁLVAREZ, L. El emplazamiento periférico de la vivienda social en el área metropolitana de Santiago de Chile: Consecuencias socioespaciales y sugerencias para modificar los criterios actuales de localización. Scripta Nova: Revista electrónica de Ciencias Sociales, 2007, Vol. $\mathrm{XI}, \mathrm{N}^{\circ}$ 245. Disponible en internet: http:// www.ub.edu/geocrit/sn/sn-24527.htm

INZULZA-CONTARDO, J. 'Latino-Gentrification'? Focusing on Physical and Socioeconomic Patterns of Change in Latin American Inner Cities. Urban Studies, 2012, Vol. 49, N 10, p. 2085-2107.

JANOSCHKA, M.; SEQUERA, J. \& SALINAS, L. Gentrification in Spain and Latin America - a Critical Dialogue. International Journal of Urban and Regional Research, (en prensa).

KANAI, M. \& ORTEGA-ALCÁZAR, I. The Prospects for Progressive Culture-Led Urban Regeneration in Latin America: Cases from Mexico City and Buenos Aires. International Journal of Urban and Regional Research, 2009, Vol. 33, N², p. 483-501.

LEES, L.; SLATER, T. \& WYLY, E. Gentrification. New York \& London: Routledge, 2008.

LEFORT, F. \& VARGAS, M. Tacit Collusion in the Santiago Housing Market. Santiago: Inter-American Development Bank, 2011.

LÓPEZ-MORALES, E. Destrucción creativa y explotación de brecha de renta: discutiendo la renovación urbana del peri-centro sur poniente de Santiago de Chile entre 1990 y 2005. Scripta Nova: Revista electrónica de Ciencias Sociales, 2008, Vol. 12, N² 270. Disponible en internet: http://www.ub.edu/ geocrit/-xcol/101.htm 
LÓPEZ-MORALES, E. Gentrification by Ground Rent Dispossession: the Shadows Cast by Large Scale Urban Renewal in Santiago de Chile. International Journal of Urban and Regional Research, 2011, Vol. 35, No 2, p. 1-28.

LÓPEZ-MORALES, E.; GASIC, I. y MEZA, D. Urbanismo Pro-Empresarial en Chile: políticas y planificación de la producción residencial en altura en el pericentro del Gran Santiago. Revista INVI, 2012, Vol. 28, N76, p. 75-114.

MACLEOD, G. From Urban Entrepreneurialism to a "Revanchist City"? On the Spatial Injustices of Glasgow's Renaissance. Antipode, 2002, Vol. 34, No 3, p. 602-624.

MARCUSE, P. Gentrification, abandonment and displacement: connections, causes and policy responses in New York City. Journal of Urban and Contemporary Law, 1985, $\mathrm{N}^{\circ} 28$, p. 195-240.

MOLOTCH, H. The Political Economy of Growth Machines. Journal of Urban Affairs, 1993, Vol. 15, N 1, p. 29-53.

NEWMAN, K. \& WYLY, E. K. The Right to Stay Put, Revisited: Gentrification and Resistance to Displacement in New York City. Urban Studies, 2006, Vol. 43, Nº1, p. 23-57.

PECK, J. Struggling with the Creative Class. International Journal of Urban and Regional Research, 2005, Vol. 29, $\mathrm{N}^{\circ} 4$, p. 740-770.

PECK, J. \& TICKEL, A. Conceptualizing Neoliberalism, Thinking Thatcherism. In: LEITNER, H.; PECK J. \& SHEPPARD E. Contesting Neoliberalism: Urban Frontiers. Nueva York: The Guildford Press, 2007, p. 26-50.

PECK, J. \& TICKEL, A. Neoliberalizing Space. Antipode, 2002, Vol. 34, № 3, p. 380404.

SABATINI, F.; VÁSQUEZ, H.; ROBLES, S. y RASSE, A. Gentrificación sin expulsión, fuerza de transformación de las ciudades latinoamericanas: datos e interpretación para Santiago. En: SABATINI, F.; SALCEDO, R.; WORMALD, G. y CÁCERES G. Tendencias de la segregación en las principales ciudades chilenas. Análisis censal 1982-2002. Santiago de Chile: Instituto Nacional de Estadísticas y Pontificia Universidad Católica de Chile, 2010, p. 165-184.

SALAZAR, G. Historia de La Acumulacion Capitalista En Chile: Apuntes de Clase. Santiago de Chile: LOM Ediciones, 2003.

SANDRONI, P.H. Renovación Urbana y Gentrificación: evaluación de algunos impactos demográficos, sociales y económicos de la operación urbana Faría Lima en la ciudad de San Pablo. Medio Ambiente y Urbanización, 2006, №65, p. 109-116.

SANDRONI, P.H. Recent experience with land value capture in São Paulo, Brazil. Land Lines, 2011, Vol. 23, №3, p. 14-19.

SCHLACK, E. y TURNBULL, N. Capitalizando lugares auténticos: Artistas y emprendimientos en la regeneración urbana. $A R Q$, 2011, No 79, p. 28-42.

SHIN, H.B. Property-based redevelopment and gentrification: The case of Seoul, South Korea. Geoforum, 2009a, Vol. 40, № 5, p. 906-917.

SHIN, H.B. Residential Redevelopment and the Entrepreneurial Local State: The Implications of Beijing's Shifting Emphasis on Urban Redevelopment Policies. Urban Studies, 2009b, Vol. 46, № 13, p. 2815-2840.

SLATER, T. The Eviction of Critical Perspectives from Gentrification Research. International Journal of Urban and Regional Research, 2006, Vol. 30, N 4, p. 737-757.

SLATER, T. Missing Marcuse: On gentrification and displacement. City - Analysis of Urban Trends Culture Theory Policy and Action, 2009, Vol. 13, № 2, p. 292-312.

SLATER, T. Still missing Marcuse: Hamnett's foggy analysis in London town. City - Analysis of Urban Trends Culture Theory Policy and Action, 2010, Vol. 14, $\mathrm{N}^{\circ}$ 1, p. 170-180.

SMITH, N. Toward a Theory of Gentrification A Back to the City Movement by Capital, 
not People. Journal of the American Planning Association, 1979, Vol. 45, № 4, p. 538-548.

SMITH, N. The new urban frontier: gentrification and the revanchist city. London- New York: Routledge, 1996.

SMOLKA, M. Una nueva mirada a la recuperación de plusvalías en América Latina. Land Lines, 2012, Vol. 24, N 3, p. 11-17.

SMOLKA, M. y AMBORSKI, D. Recuperación de plusvalías para el desarrollo urbano: una comparación inter-americana. EURE, 2003, Vol. 29, No 88, p. 55-77.

SWYNGEDOUW, E. The Antinomies of the Postpolitical City: In Search of a Democratic Politics of Environmental Production. International Journal of Urban and Regional Research, 2009, Vol. 33, №3, p. 601-620.
TRIVELLI, P. La propuesta de modificación del Plan Regulador Metropolitano de Santiago PRMS 100 requiere una justificación más sólida. EURE, 2011, Vol. 37, N 111, p. 179184.

WACQUANT, L. Relocating Gentrification: The Working Class, Science and the State in Recent Urban Research. International Journal of Urban and Regional Research, 2008, Vol. 32, No 1, p. 198-205.

WARD, K. Entrepreneurial urbanism, state restructuring and civilizing ' $\mathrm{New}^{\prime}$ East Manchester. Area - London, 2003, Vol. 35, № 2, p. 116-128.

WYLY, E.; NEWMAN, K.; SCHAFRAN, A. \& LEE, E. Displacing New York. Environment and Planning A, 2010, Vol. 42, $N^{\circ} 11$, p. 2602-2623. 